\title{
Ex vivo analysis of topotecan: advancing the application of laboratory-based clinical therapeutics
}

\author{
RA Nagourney*, I,2 , BL Sommers', SM Harper', S Radecki ${ }^{3}$ and SS Evans' \\ 'Rational Therapeutics, Inc., 750 East 29th Street, Long Beach, CA 90806, USA; ${ }^{2}$ Malcolm C. Todd Cancer Institute, 280 I Atlantic Avenue, Long Beach, \\ CA 90806, USA; ${ }^{3}$ College of Medicine at University of California, Irvine
}

\begin{abstract}
Topotecan is currently approved for relapsed small-cell lung cancer and ovarian cancer. Topotecan's efficacy in the second-line setting and novel mechanism of action suggest broad antitumour activity. We utilised a clinically validated, cell-death, ex vivo assay in human tumour explants to examine the activity profile of topotecan alone and in combination with other antitumour agents. Serial dilutions of topotecan alone and in combination with other cytotoxic agents were applied to biopsy specimens of non-small-cell lung cancer (NSCLC) and breast, colon, and prostate cancers. Dose-response curves were interpolated to provide $50 \%$ lethal concentrations $\left(L C_{50}\right)$. The degree of synergy (by median effect) and normalised Z-scores (raw scores converted to relative activity distributed around the mean) were then computed. Single-agent activity was observed for topotecan in all four tumour types. In 57 chemotherapy-naive specimens, NSCLC revealed the highest activity, demonstrated by the lowest $L_{50}$ value $\left(0.26 \pm 0.06 \mu \mathrm{g} \mathrm{ml}{ }^{-1}\right.$; $P=0.002)$. Overall, previously treated and chemotherapy-naive specimens revealed no significant differences in mean $L_{50} C_{5}$. Synergy was observed for several combinations, including topotecan plus cisplatin in prostate and for topotecan plus 5-fluorouracil in breast cancers. The Z-score analyses conducted suggest activity for previously unexplored drug regimens, including topotecan plus 5fluorouracil, vinorelbine, and mitomycin-C in NSCLC and breast cancer. Phase II studies are underway to determine the degree to which these ex vivo findings will translate into improved clinical results.
\end{abstract}

British Journal of Cancer (2003) 89, I789- 1795. doi:I0.1038/sj.bjc.6601336 www.bjcancer.com

(c) 2003 Cancer Research UK

Keywords: topotecan; combination regimens; non-small-cell lung cancer; breast cancer; cell-death assay; ex vivo

Topotecan, a semisynthetic, water-soluble derivative of camptothecin, is an inhibitor of topoisomerase I (Kingsbury et al, 1991). This derivative is more stable, has increased solubility, a shorter half-life, and decreased toxicity compared with its parent compound (Verweij et al, 1993; Burke and Mi, 1994; Rothenberg, 1997). Topoisomerase I is a nuclear enzyme that relieves torsional strain on supercoiled DNA and creates single-strand breaks during DNA replication. Topotecan prevents topoisomerase I from repairing the cleaved DNA, which results in double-stranded DNA breaks and eventually apoptosis. The unique mechanism of action of topotecan and lack of clinical crossresistance with other antineoplastic compounds suggest that topotecan has the potential for broad antitumour activity.

The activity of topotecan has been demonstrated in several open-label, randomised phase II and III trials. Currently, topotecan is approved for the treatment of relapsed small-cell lung cancer (SCLC) (Eckardt et al, 1996; Ardizzoni et al, 1997; Depierre et al, 1997; von Pawel et al, 1999, 2001) and ovarian cancer (Creemers et al, 1996; Kudelka et al, 1996; ten Bokkel Huinink et al, 1997; Bookman et al, 1998; Hoskins et al, 1998; McGuire et al, 2000). Although topotecan is typically given in a 30min intravenous (i.v.) infusion on days $1-5$ of a 21-day course,

\footnotetext{
*Correspondence: Dr RA Nagourney,

E-mail: robert.nagourney@rationaltherapeutics.com

Received 22 May 2003; revised 20 August 2003; accepted 28 August 2003
}

other clinical schedules have been investigated, including 21-day continuous i.v. infusion (Hochster et al, 1999), 3-day administration (Brown et al, 2000), single-day administration every 21 days (Wall et al, 1992), weekly bolus (Homesley et al, 2001), and weekly 24-h continuous i.v. infusion (Hoskins et al, 1998). In addition, an oral formulation of topotecan has also been investigated in SCLC (von Pawel et al, 2001) and ovarian cancer (Clarke-Pearson et al, 2001). Preliminary reports indicate that topotecan also has activity in non-small-cell lung cancer (NSCLC) (Lynch et al, 1994; PerezSoler et al, 1996), cervical cancer (Fiorica et al, 2002), and haematologic malignancies (Beran et al, 1998). Additional studies are required to determine the activity of topotecan in other cancers.

Topotecan activity also suggests potential for synergy in combination with other cytotoxic agents. The predictable toxicity profile of topotecan makes it feasible to combine topotecan with other agents with nonoverlapping toxicities. Topotecan has been investigated in doublet and triplet combinations with several agents, including cisplatin, paclitaxel, and etoposide (Ardizzoni et al, 1999; Frasci et al, 1999; Hainsworth et al, 1999; Jacobs et al, 1999; O’Neill et al, 2001; Fiorica et al, 2002). Randomised trials are underway in several diseases to evaluate the efficacy of topotecan in combination with other agents.

Ex vivo analyses of human tumour primary cultures can provide disease-specific drug activity profiles and powerful insights useful in the development of phase I/II trials. The present study applied an ex vivo assay, based on the delayed loss of membrane integrity, to investigate the clinical potential of topotecan in human tumour 
biopsy specimens other than relapsed SCLC and ovarian cancer. Although earlier laboratory assays based on drug-induced growth inhibition (e.g. $\mathrm{H}_{3}{ }^{*}$-thymidine incorporation, clonogenic) have consistently failed to provide clinically relevant information, newer methods that incorporate cell-death measures as surrogates of drug-induced apoptosis have been shown to correlate with response, time to progression, and survival in human haematologic and solid tumours (Bosanquet et al, 1999; Cortazar and Johnson, 1999; Nagourney et al, 2000, 2003). The realisation that most chemotherapeutic agents exert their cytotoxic effects through apoptosis (Reed, 1999) supports the use of cell-death assay in the study of topotecan's antitumour activity in human neoplasms.

The principal focus of this study was the investigation of topotecan activity in biopsies of previously untreated NSCLC and breast, colorectal, and prostate carcinomas. We also assessed the synergy of topotecan in combination with other antineoplastic agents and compared the activity of topotecan in chemotherapynaive $v s$ previously treated specimens. Additional analyses compared the activity of topotecan with that of irinotecan, the related topoisomerase I inhibitor, in parallel studies.

\section{MATERIALS AND METHODS}

\section{Tissue procurement and tumour-cell preparation}

Patients undergoing surgical procedures for the management of NSCLC and breast, colorectal, or prostate cancers were offered the opportunity to participate in the study. All patients provided written informed consent allowing the release of tumour biopsy specimens for laboratory analysis. At the time of surgical exploration, tumour tissues removed from the patients were processed sterilely by the Department of Pathology at the Long Beach Memorial Medical Centre (Long Beach, CA, USA). After histologic diagnostic evaluations, the tissue samples were placed in sterile RPMI 1640 media containing $2 \mathrm{~mm}$ L-glutamine, $15 \%$ fetal calf serum, $100 \mathrm{IU} \mathrm{ml}^{-1}$ penicillin, and $100 \mu \mathrm{g} \mathrm{ml}^{-1}$ streptomycin (modified RPMI 1640), and were submitted directly to our laboratory. Samples obtained after hours were maintained at $4{ }^{\circ} \mathrm{C}$ until processed (always $<24 \mathrm{~h}$ ). This study was approved by the Long Beach Memorial Medical Centre Human Subjects Committee.

Tumour specimens were mechanically disaggregated by sterile mincing with scalpels. Specimens were then incubated for $2 \mathrm{~h}$ in $0.8 \%$ collagenase IV and $0.002 \%$ DNase I. Cells were isolated by density centrifugation over Ficoll-Hypaque, washed, and then resuspended in modified RPMI 1640. Cell suspensions were adjusted to $1 \times 10^{6}$ cells ml $^{-1}$ and distributed into 96-well polypropylene culture plates $\left(90 \mu \mathrm{lwell}^{-1}\right)$. Serial dilutions of drugs and drug combinations in $10 \mu \mathrm{l}$ volumes were added, and the plates were incubated at $37^{\circ} \mathrm{C}$ in $6 \% \mathrm{CO}_{2}$ in a sterile, humidified environment for $72 \mathrm{~h}$ as described in the next section.

\section{Drug exposure and measurement of cell viability}

The dose-dependent cytotoxicity of drugs was investigated using a five-point dose-response curve. Serial dilutions of cytotoxic drugs were prepared in $0.15 \mathrm{M} \mathrm{NaCl}$, and $10 \mu \mathrm{l}$ of a drug solution was added to each well. Cells were incubated for $72 \mathrm{~h}$ with saline vehicle control $(0.15 \mathrm{M} \mathrm{NaCl})$ or in the presence of topotecan (range, 0.03 $0.92 \mu \mathrm{g} \mathrm{ml}^{-1}$ ), alone or in combination at a fixed ratio in serial dilution with 5-fluorouracil (5-FU; range, 3.1-100 $\mu \mathrm{g} \mathrm{ml}^{-1}$ ), cisplatin (range, $0.2-6.6 \mu \mathrm{g} \mathrm{ml}^{-1}$ ), doxorubicin (range, 0.04$1.2 \mu \mathrm{g} \mathrm{ml}^{-1}$ ), gemcitabine (range, $8.2-263 \mu \mathrm{g} \mathrm{ml}^{-1}$ ), mitomycin-C (range, $0.04-1.2 \mu \mathrm{g} \mathrm{ml}^{-1}$ ), mitoxantrone (range, $0.03-1.0 \mu \mathrm{g} \mathrm{ml}^{-1}$ ), nitrogen mustard (range, $0.17-5.4 \mu \mathrm{g} \mathrm{ml}^{-1}$ ), oxaliplatin (range, $0.3-10 \mu \mathrm{g} \mathrm{ml}^{-1}$ ), paclitaxel (range, $1.6-50 \mu \mathrm{g} \mathrm{ml}^{-1}$ ), or vinorelbine (range, $0.3-10 \mu \mathrm{g} \mathrm{ml}^{-1}$ ). After $72 \mathrm{~h}, 10 \mu \mathrm{l}$ of phosphate-buffered saline containing $0.5 \%$ nigrosin-B and $1 \%$ Fast Green and 37500 glutaraldehyde-fixed avian red blood cells (internal standard) were added to each well, and the samples were gently agitated to facilitate mixing. After $10 \mathrm{~min}$, samples were aspirated and centrifuged onto a glass slide using a modified cytospin cassette. Air-dried samples were counterstained with modified haematoxylin and eosin. Tumour cell viability was determined as the ratio of living tumour cells over simultaneously counted avian red blood cells. Cell survival of drug-treated samples was expressed as a percentage of saline control values.

\section{Calculation of $\mathrm{LC}_{50}$, synergy, and $Z$-score}

The $50 \%$ lethal concentration $\left(\mathrm{LC}_{50}\right)$ values were calculated using a least-squares line of best-fit generated from the five-point concentration curve, with the $\mathrm{LC}_{50}$ values interpolated from the curve. Synergy was determined using the median effect technique (Chou and Talalay, 1987, pp 37-64). In brief, dose-response curves and $\mathrm{LC}_{50}$ values were generated for topotecan both as a single agent and in combination with other agents. Comparison of the topotecan single-agent dose-response curves with the combination dose-response curves for a given tumour type allowed the determination of synergy, additivity, subadditivity, or antagonism. The term synergy only applied to tumour samples with $100 \%$ of the points on the combination dose-response curves falling above the line of additivity, while partial synergy applied to samples for which $>50 \%$ of the points on the dose-response curve were above the line of additivity.

The overall mean $\mathrm{LC}_{50}\left(\mathrm{LC}_{50} \mathrm{~T}\right)$ and s.e.m. for all tumour types (s.e.m T) within our laboratory database were utilised to calculate $Z$-scores by the following formula:

$$
\frac{\left(\mathrm{LC}_{50} \text { sample }-\mathrm{LC}_{50} \mathrm{~T}\right)}{\text { s.e.m.T }}
$$

The use of inferential statistics is predicated upon the central limit theorem (Feinstein, 1998), a fundamental sampling theorem that states that the distribution of a sample population is unimportant so long as the samples are drawn randomly in sufficient numbers from a parent population whose distribution need not have a normal (Gaussian) distribution (Hays, 1994).

By normalising the $\mathrm{LC}_{50}$ values for each single agent and/or combination around the mean $\mathrm{LC}_{50}$ values, samples found to be more resistant than average fell to the right of the mean, whereas those that were more sensitive than average fell to the left of the mean. This $Z$-score transformation is routinely used in the US by the National Cancer Institute for studies comparing microarray data and other analyses (Cheadle et al, 2003). It has been incorporated into the COMPARE statistical program (Shi et al, 1998), and into the latest version of the National Cancer Institute's public access MAExplorer bioinformatics tool (Lemkin et al, 2000).

\section{STATISTICAL METHODS}

Statistical analysis of the study data was carried out using the analysis of variance program from the Statistical Package for the Social Sciences (Levine, 1991). The $\mathrm{LC}_{50}$ means for single-agent topotecan in untreated biopsies were compared across tumour types, with the criterion for statistical significance set at $P \leqslant 0.05$. For comparisons of in vitro activity of topotecan in combination with other agents, $\mathrm{LC}_{50}$ values were normalised into $Z$-scores (with the mean set to 0 and variance from the mean in s.e.m. units of 1) (Kirk, 1982). This permitted direct comparisons of the sensitivity $v s$ resistance of drug combinations across tumour types. Using these normalised $\mathrm{LC}_{50}$ values, graphic representations were generated depicting on the left side of the mean those samples more sensitive than average to drug combinations (negative range), and on the right side of the mean those more resistant than average to drug combinations (positive range). Finally, the activity of topotecan $v s$ irinotecan in tumour specimens was 
assessed using a scatter gram graph and was statistically compared using the Pearson product-moment correlation from the same statistical package.

\section{RESULTS}

\section{Activity of single-agent topotecan}

In aggregate, our topotecan database includes a total of 697 analyses, of which 380 are from NSCLC, and breast, colon, and prostate cancer biopsies that have been studies against single-agent topotecan. These include 149 specimens from chemotherapy-naive patients (untreated specimens) and 231 specimens from previously treated patients (previously treated specimens).

To assess the effect of prior chemotherapy exposure on the activity of topotecan, the $\mathrm{LC}_{50}$ values of topotecan in cells obtained from previously treated specimens were compared with those from untreated specimens (Figure 1). The mean $\mathrm{LC}_{50}$ value for all previously treated specimens was only marginally higher than that for the untreated specimens. However, when comparing previously treated $\mathrm{LC}_{50}$ values with untreated $\mathrm{LC}_{50}$ values within tumour types, several trends emerged. For instance, a comparison between the $\mathrm{LC}_{50}$ values of 135 previously treated breast cancer specimens with 33 untreated breast cancer specimens indicated a trend toward greater sensitivity in the previously treated specimens. The opposite trend was observed in colon cancer and NSCLC specimens. By rank order, previously untreated NSCLC specimens exhibited the lowest $\mathrm{LC}_{50}$ value $(P=0.002)$, whereas previously untreated prostate cancer specimens had the highest $\mathrm{LC}_{50}$ value, suggesting that NSCLC and breast cancer might be better targets for topotecan than colon or prostate cancers.

To address concerns that prior exposure to chemotherapy might pose a confounding variable, we procured 86 tumour specimens from previously untreated patients to conduct formal drug response and combination analyses. Viable tumour cells were successfully isolated from $74(86 \%)$ of these specimens. Of 74

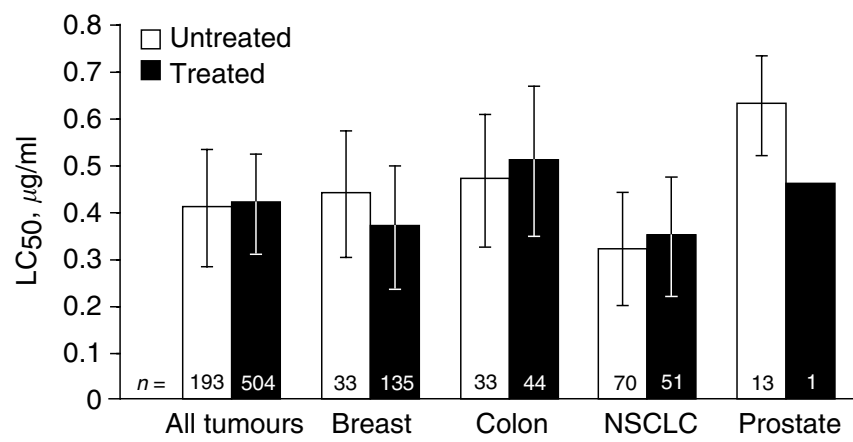

Figure I $L C_{50}$ values for single-agent topotecan in tumour biopsies taken from untreated and previously treated patients in the master database. Tumour biopsies from patients with breast cancer, colon cancer, NSCLC, or prostate cancer were incubated with various concentrations of topotecan, and the $\mathrm{LC}_{50}$ values were calculated. The numbers in parentheses indicate the number of samples for the indicated drug combination. specimens, 57(77\%), including 14 NSCLC and 18 breast, 13 prostate, and 12 colon cancer specimens, provided adequate cell yield for complete single-agent and a combination-agent analyses. Of the 74 specimens, $17(23 \%)$ provided adequate cell yield for partial analyses. The $\mathrm{LC}_{50}$ value $( \pm$ s.e.m.) for single-agent topotecan in all 57 tumours was $0.43 \pm 0.04 \mu \mathrm{g} \mathrm{ml}^{-1}$. The $\mathrm{LC}_{50}$ values for each tumour type are shown in Table 1 . The NSCLC samples demonstrated the lowest $\mathrm{LC}_{50}$ value at $0.26 \pm 0.06 \mu \mathrm{g} \mathrm{ml}^{-1}$ $(P=0.002)$, suggesting that NSCLC is a potential target for topotecan treatment.

\section{Synergy of topotecan combinations}

The mechanism of action of topotecan suggests that combinations with other cytotoxic agents may provide increased antitumour activity. To assess this potential, a variety of topotecan-drug combinations were investigated for activity and degree of synergy. The $\mathrm{LC}_{50}$ values for topotecan in combination with other agents, at fixed drug ratios, and the degree of synergy for the different drug combinations by tumour type are provided in Table 2 . It is worth noting that the degree of synergy varied by drug combination and tumour type.

\section{$Z$-scores of topotecan combinations}

Ex vivo drug concentrations were based on the clinically correlated database. Concentration ranges, by drug, varied by as much as three orders of magnitude. To compare antitumour activity in highly disparate concentration ranges directly, raw $\mathrm{LC}_{50}$ values were normalised using $Z$-scores, as summarised in Table 2 and illustrated in Figures 2 and 3. The data used in the generation of the s.e.m. values were obtained in previously untreated solid tumours in the laboratory database. These included NSCLC, colon, gastric, breast, ovarian, pancreatic, and uterine cancer specimens, ranging in number from 17 (mitoxantrone) to 53 (vinorelbine) with a median of 35 analyses per drug combination. A variety of combination regimens fell within the sensitive range of $Z$-scores for breast cancer and NSCLC tumour samples. The combination of doxorubicin and topotecan revealed significantly different $Z$ scores between breast and prostate cancer $(P<0.001)$. Likewise, a comparison of prostate cancer, colon cancer, and NSCLC samples revealed significant differences in $Z$-scores across these tumour types for the combination of topotecan and oxaliplatin $(P<0.01)$. Analyses of variance conducted across the four tumour types revealed significant differences in $Z$-scores for the topotecan/ cisplatin combination $(P<0.05)$. Finally, the topotecan/mitomycin-C combination resulted in significantly different $Z$-scores between NSCLC and colon cancer tumour samples $(P<0.01)$. Only two combination regimens (topotecan/cisplatin and topotecan/ nitrogen mustard) demonstrated $Z$-scores in the sensitive range in prostate cancer samples. None of the drug combinations tested on colon cancer samples had $Z$-scores within the sensitive range.

\section{Topotecan $v s$ irinotecan}

A unique advantage of these ex vivo analyses is their ability to compare drugs in parallel studies conducted on individual patient

Table I $\quad \mathrm{LC}_{50}\left(\mu \mathrm{g} \mathrm{ml}^{-1}\right)$ values for single-agent topotecan in untreated biopsies by tumour type

\begin{tabular}{lccccc}
\hline & All tumours, $\boldsymbol{n}=\mathbf{5 7}$ & Breast, $\boldsymbol{n}=\mathbf{I 8}$ & Colon, $\boldsymbol{n}=\mathbf{I 2}$ & NSCLC, $\boldsymbol{n}=\mathbf{I 4}$ & $\mathbf{P r o s t a t e , ~} \boldsymbol{n}=\mathbf{I 3}$ \\
\hline Mean \pm s.d. & $0.43 \pm 0.30$ & $0.40 \pm 0.25$ & $0.47 \pm 0.31$ & $0.26 \pm 0.22 *$ & $0.63 \pm 0.22$ \\
Median & 0.35 & 0.30 & 0.40 & 0.20 & 0.50 \\
\hline
\end{tabular}

$\mathrm{LC}_{50}=50 \%$ lethal concentration; NSCLC $=$ non-small-cell lung cancer; s.d. = standard deviation. $* P<0.002$. (t-test, comparing NSCLC to other tumour types). 
Table 2 In vitro activity of topotecan in combination with other agents

\begin{tabular}{|c|c|c|c|}
\hline Diagnosis $(n)$ & Mean $\mathrm{LC}_{50}\left(\mu \mathrm{g} \mathrm{ml}^{-1}\right)$ & Synergy *(\%) & Z-score \\
\hline \multicolumn{4}{|l|}{ 5-fluorouracil } \\
\hline Breast (9) & 13.21 & 57 & -1.70 \\
\hline Colon (12) & 18.37 & 15 & +0.46 \\
\hline NSCLC (3) & 25.00 & 0 & +3.25 \\
\hline \multicolumn{4}{|l|}{ Cisplatin } \\
\hline Breast (9) & 1.44 & 13 & +2.31 \\
\hline Colon (II) & 1.67 & 17 & +4.17 \\
\hline NSCLC (20) & 0.88 & 31 & -2.28 \\
\hline Prostate (4) & 0.88 & 75 & -2.32 \\
\hline \multicolumn{4}{|l|}{ Doxorubicin } \\
\hline Breast (17) & 0.34 & 25 & -1.76 \\
\hline Prostate (14) & 0.61 & 25 & +0.082 \\
\hline \multicolumn{4}{|l|}{ Gemcitabine } \\
\hline Breast (10) & 51.10 & 0 & -1.32 \\
\hline Colon (II) & 65.18 & 27 & +1.25 \\
\hline NSCLC (I8) & 45.61 & 7 & -2.32 \\
\hline Prostate (10) & 81.0 & 0 & +4.13 \\
\hline \multicolumn{4}{|l|}{ Mitomycin-C } \\
\hline Colon (10) & 0.96 & 40 & +3.88 \\
\hline $\operatorname{NSCLC~(16)~}$ & 0.45 & 38 & -2.43 \\
\hline \multicolumn{4}{|l|}{ Mitoxantrone } \\
\hline Breast (9) & 0.32 & 17 & -1.10 \\
\hline Prostate (8) & 0.46 & 25 & +1.24 \\
\hline \multicolumn{4}{|l|}{ Nitrogen mustard } \\
\hline Breast (17) & 1.11 & 25 & +0.24 \\
\hline NSCLC (3) & 0.97 & 0 & -0.98 \\
\hline Prostate (4) & 1.05 & 25 & -0.28 \\
\hline \multicolumn{4}{|l|}{ Oxaliplatin } \\
\hline Colon (10) & 2.59 & 22 & +0.76 \\
\hline $\operatorname{NSCLC~(16)~}$ & 1.53 & 8 & -3.13 \\
\hline Prostate (10) & 3.52 & 20 & +4.18 \\
\hline \multicolumn{4}{|l|}{ Paclitaxel } \\
\hline Breast (13) & 6.73 & 33 & -0.38 \\
\hline $\operatorname{NSCLC}(19)$ & 7.98 & 0 & +1.59 \\
\hline \multicolumn{4}{|l|}{ Vinorelbine } \\
\hline Breast (13) & 2.04 & 25 & -1.36 \\
\hline Colon (II) & 2.96 & 27 & +2.76 \\
\hline $\operatorname{NSCLC~(19)~}$ & 1.82 & 13 & -2.33 \\
\hline Prostate (10) & 3.05 & 25 & +3.15 \\
\hline
\end{tabular}

*Defined as the percentage of tumour samples that demonstrated 100\% synergy as described in Materials and Methods section. $L C_{50}=50 \%$ lethal concentration; $\mathrm{NSCLC}=$ non-small-cell lung cancer.

tumour specimens. Irinotecan, another topoisomerase I inhibitor, is a prodrug activated by carboxylesterase to form the active metabolite SN38. While spontaneous degradation or activation by carboxylesterases present in culture media is known to occur, and provides cytotoxic activity in vitro, some variability between irinotecan and topotecan would be expected based on topotecan's direct cytotoxic actions. When we directly compared the activity of topotecan against that of irinotecan in 239 chemonaive and previously treated human tumour specimens, there was a significant correlation between the $\mathrm{LC}_{50}$ values for topotecan $v s$ irinotecan $(P<0.0005)$. At the time of initial calculation, a portion of the $\mathrm{LC}_{50}$ values were rounded to the nearest $0.1 \mu \mathrm{g} \mathrm{ml}^{-1}$ value.

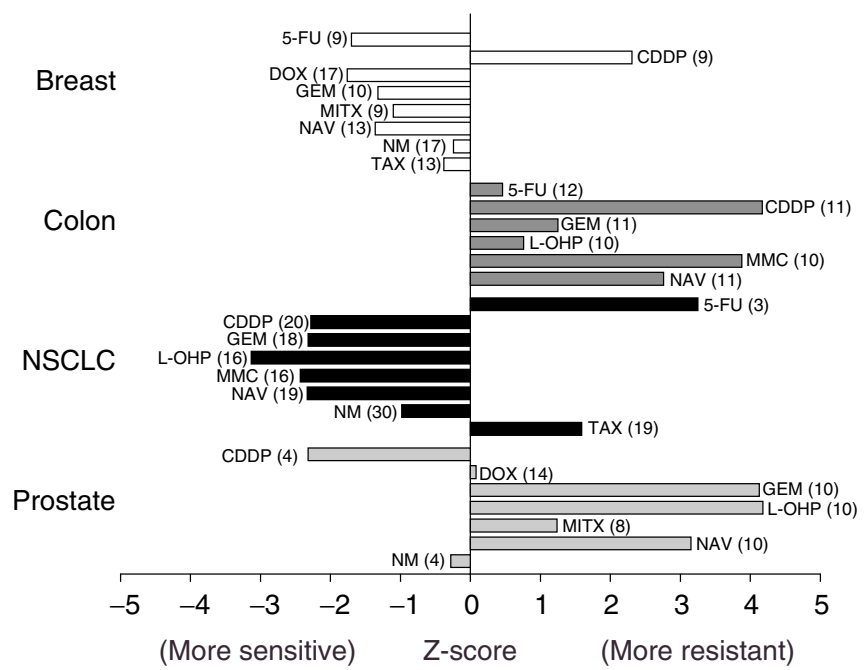

Figure 2 Z-scores of topotecan combination regimens in four tumour types. Z-scores of topotecan in biopsies from patients with breast cancer (open), colon cancer (dark grey), NSCLC (black), and prostate cancer (light grey). The numbers in parentheses indicate the number of samples for the indicated drug combination. NSCLC = non-small-cell lung cancer; 5$\mathrm{FU}=5$-fluorouracil; $\quad \mathrm{CDDP}=$ cisplatin; $\quad \mathrm{DOX}=$ doxorubicin GEM = gemcitabine; $M I T X=$ mitoxantrone; NAV = vinorelbine; $N M=n i-$ nitrogen mustard; $\mathrm{TAX}=$ paclitaxel; $\mathrm{L}-\mathrm{OH} P=$ oxaliplatin; $\mathrm{MMC}=\mathrm{mi}-$ mitomycin-C.

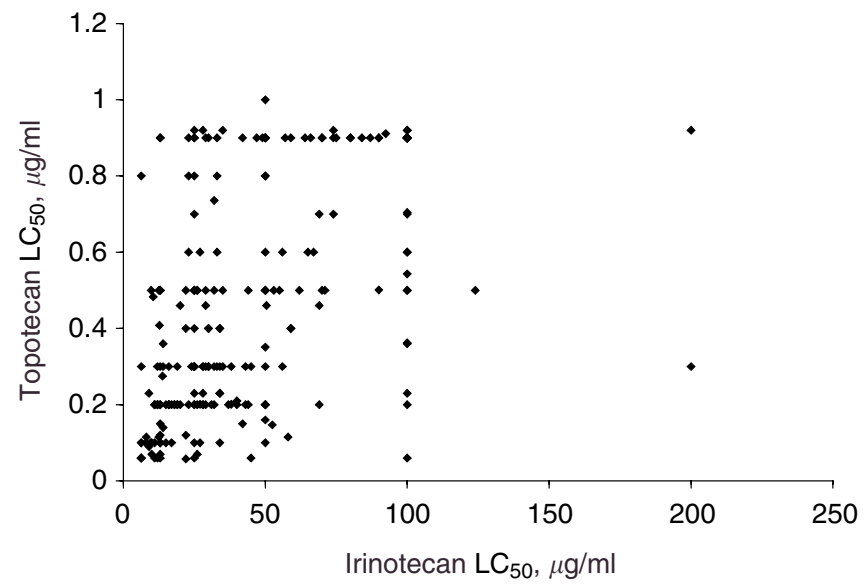

Figure 3 Relative in vitro activity of topotecan vs irinotecan. A scatterplot of the $50 \%$ lethal concentration values for topotecan and irinotecan in 239 tumour biopsy samples. A correlation coefficient of 0.54 indicates significant correlation between the antitumour activity of topotecan and irinotecan in vitro $(P<0.0005)$.

\section{DISCUSSION}

The clinical efficacy and favourable safety profile of topotecan in the treatment of relapsed SCLC and ovarian cancer patients, and topotecan's novel mechanism of action have prompted investigations into its use in other solid tumours. Ex vivo analyses, based on clinically validated end points, can identify disease-specific drug activity profiles and offer a rational approach to drug development. We applied ex vivo analyses to evaluate the activity of singleagent topotecan and topotecan combinations in human NSCLC and breast, colon, and prostate cancer specimens.

Ex vivo topotecan activity was highest for NSCLC and breast cancer specimens and lowest for prostate and colon cancer 
specimens. This suggests that NSCLC may be more sensitive to single-agent topotecan than prostate cancers.

Several phase II trials have investigated the use of topotecan in the treatment of advanced NSCLC. Perez-Soler et al (1996) and Weitz et al (2000) reported overall response rates of 15 and $16 \%$, respectively, in patients treated with topotecan, and Lynch et al (1994) reported stable disease in 55\%. In contrast, and consistent with the results of the current study, single-agent topotecan has shown less promise in patients with metastatic, hormonerefractory prostate cancer (Hudes et al, 1995). The synergy results for prostate and other cancers may nonetheless offer fertile avenues for future investigations with topotecan. A possible explanation for the difference between in vitro and in vivo activity of single-agent topotecan in NSCLC is a pharmacokinetic effect. The inherent activity (reflected ex vivo) for topoisomerase I inhibitors may not be optimally exploited using current administration schedules. Recent observations with alternative schedules - including oral, long-term i.v., or the weekly administration of topotecan - suggest that these regimens may prove superior to the current 5-day topotecan schedules in those diseases that are most inherently sensitive to topotecan, with NSCLC appearing to be an attractive target.

In our study, several topotecan combinations demonstrated synergy. Among the most active combinations was that of topotecan plus 5-FU in breast cancer, which demonstrated synergy in $57 \%$ of specimens. It must be noted that the degree of synergy (combinatorial advantage) is independent of the relative antitumour activity (i.e. $\mathrm{LC}_{50}$ ). However, synergy, defined as pharmacologic supraadditivity, may occur at $\mathrm{LC}_{50}$ values that have no clinical relevance. Therefore, it is advantageous to examine the degree of synergy in the context of the relative activity, and $Z$-scores facilitate this comparison. The $Z$-score for topotecan/5-FU in breast cancer fell in the sensitive range. Based on both synergy and sensitivity (by $Z$-score) findings for this combination in breast cancer patients, a phase II clinical trial has been initiated (phase II study of topotecan plus capecitabine for recurrent, locally advanced or metastatic breast cancer). This study will examine the clinical activity of this combination and correlate clinical response with ex vivo results for each patient.

To date, breast cancer has not been a target for topotecan therapy. Levine et al (1999) reported a response rate of $10 \%$ in a study of topotecan in relapsed breast cancer conducted by the Cancer and Leukaemia Group B. However, Japanese investigators reported a $23 \%$ response rate for the closely related irinotecan in patients with advanced breast cancer (Taguchi et al, 1994). The irinotecan schedules (based on weekly dosing) compared with the topotecan schedules (based on consecutive 5-day dosing) may, in part, explain the differences in overall response rates. By modifying the topotecan schedule to days 1 and 8 , we more closely approximate the irinotecan administration schedule in our current study. The concordance between irinotecan and topotecan observed in our parallel analyses suggest that future ex vivo analyses could compare topotecan with other topoisomerase I inhibitors (e.g. 9-aminocamptothecin or 9-nitrocamptothecin).

Several topotecan combinations demonstrated synergy in NSCLC specimens, including topotecan/mitomycin-C (38\%) and topotecan/cisplatin (31\%). Both combinations revealed favourable $Z$-scores. Preliminary results for topotecan/cisplatin in NSCLC patients have provided overall response rates ranging from 14 to $31 \%$ (Raymond et al, 1997; Wiesenfeld et al, 1997). The high incidence of haematologic and nonhaematologic toxicity limited the use of this combination. Alternate dosing schedules for

\section{REFERENCES}

Ardizzoni A, Hansen H, Dombernowsky P, Gamucci T, Kaplan S, Postmus P, Giaccone G, Schaefer B, Wanders J, Verweij J (1997) Topotecan, a new active drug in the second-line treatment of small-cell lung cancer: a topotecan/cisplatin, or the substitution of carboplatin for cisplatin, might prove more tolerable. A phase II study of topotecan/ carboplatin in NSCLC patients provided a clinical benefit in $49 \%$ of patients and a 1-year survival rate of $32 \%$ (Pujol et al, 2001). No episodes of nephrotoxicity, ototoxicity, or neurotoxicity were reported. Although synergy was demonstrated in $<20 \%$ of specimens in NSCLC for topotecan/vinorelbine, the $Z$-scores for this combination, and those for topotecan/gemcitabine, fell within the sensitive range. Vinorelbine provides single-agent activity with overall response rates ranging from 12 to $20 \%$ in NSCLC (Crawford et al, 1996; The Elderly Lung Cancer Vinorelbine Italian Study Group, 1999). The ex vivo results revealing activity for topotecan/ vinorelbine in NSCLC are consistent with the report of Stupp et al (2001), which provided a response rate of $42 \%$ in NSCLC patients treated with this combination

Ex vivo activity profiles also provide the opportunity to develop novel triplet regimens. The favourable activity observed for the doublets of topotecan plus cisplatin and topotecan plus gemcitabine paralleled our ex vivo results for the three-drug combination in NSCLC specimens (unpublished observations). Guarino et al (2002) reported a $38 \%$ objective response rate and 1-year survival of $33 \%$ in patients with NSCLC who received this weekly regimen. Toxicity was extremely mild with only one of 30 patients experiencing a grade IV adverse event (leukopenia). A second phase II trial is under final development to further evaluate this triplet in NSCLC (phase II study of hycamtin, cisplatinum, and gemcitabine in advanced NSCLC).

Several other observations were of interest. Despite the low single-agent activity of topotecan in prostate cancer specimens, the favourable degrees of synergy and activity for topotecan/cisplatin in this disease could provide insights for future investigation. On the contrary, the high degree of synergy for topotecan/mitomycin$\mathrm{C}$ in colon cancer specimens when combined with the resistant $Z$ score for this combination in colon specimens argues against clinical evaluation. Although single-agent topotecan is widely used for the treatment of relapsed ovarian cancer, combinations identified in this study may offer additional insights. The high degree of synergy that we reported previously for topotecan/ gemcitabine in ovarian cancer specimens (Su et al, 2001) is supported by the results of a phase II study, in which seven of 11 (64\%) patients with relapsed ovarian cancer achieved objective responses with this combination (Sehouli et al, 2001). Topotecan combinations might also be investigated in diseases that are historically resistant to chemotherapy. Fiorica et al (2002) reported a $28 \%$ (nine of 32 ) overall response rate for topotecan/cisplatin in patients with recurrent cervical cancer.

In summary, topotecan reveals activity in human NSCLC and in breast, prostate, and colon cancer primary cultures. Previously, unrecognised synergy between topotecan and other agents have allowed the development of novel phase II clinical trials in NSCLC and breast cancers. Trials are also in development to evaluate topotecan in cervical, colorectal, prostate, and haematologic malignancies.

\section{ACKNOWLEDGEMENTS}

We acknowledge the technical assistance of Craig Chou, Yong Zhuang Su, Cheryl Kollin Dorothy Horlick. This work was supported by GlaxoSmithKline, Philadelphia, PA, USA. We gratefully acknowledge the financial support of GlaxoSmithKline (Philadelphia, PA, USA).

phase II study in patients with refractory and sensitive disease. J Clin Oncol 15: $2090-2096$ 
Ardizzoni A, Manegold C, Gaafar R, Buchholdz E, Debruyne C, Damen S, Curran D, King K, Giaccone G (1999) Combination chemotherapy with cisplatin and topotecan as second-line treatment of sensitive $(S)$ and refractory (R) small cell lung cancer (SCLC): an EORTC LCCG phase II study (abstract). Proc Am Soc Clin Oncol 18: 471a

Beran M, Estey E, O’Brien SM, Giles FJ, Koller CA, Kornblau S, Keating M, Kantarjian HM (1998) Results of topotecan single-agent therapy in patients with myelodysplastic syndromes and chronic myelomonocytic leukemia. Leukemia Lymphoma 31: 521-531

Bookman MA, Malmström H, Bolis G, Gordon A, Lissoni A, Krebs JB, Fields SZ (1998) Topotecan for the treatment of advanced epithelial ovarian cancer: an open-label phase II study in patients treated after prior chemotherapy that contained cisplatin or carboplatin and paclitaxel. J Clin Oncol 16: 3345-3352

Bosanquet AG, Johnson SA, Richards SM (1999) Prognosis for fludarabine therapy of chronic lymphocytic leukaemia based on ex vivo drug response by DISC assay. Br J Haematol 106: $71-77$

Brown III JV, Peters III WA, Rettenmaier MA, Karlan BY, Dillman RA, Smith MR, Drescher CW, Micha JP (2000) A phase I trial of a 3-day topotecan q 21 days for recurrent epithelial cancers of the ovary, fallopian tube, and peritoneum. Gynecol Oncol 79: 495-498

Burke TG, Mi Z (1994) The structural basis of camptothecin interactions with human serum albumin: impact on drug stability. J Med Chem 37: $40-46$

Cheadle C, Vawter MP, Freed WJ, Becker KG (2003) Analysis of microarray data using $Z$ score transformation. J Mol Diagn 5: 73-81

Chou T-C, Talalay P (1987) Applications of the median-effect principle for the assessment of low-dose risk of carcinogens and for the quantitation of synergism and antagonism of chemotherapeutic agents. In New Avenues in Developmental Cancer Chemotherapy Harrap KR, Connors TA (eds) pp 37-64. Orlando, FL: Academic Press Inc.

Clarke-Pearson DL, Van Le L, Iveson T, Whitney CW, Hanjani P, Kristensen G, Malfetano JH, Beckman RA, Ross GA, Lane SR, DeWitte MH, Fields SZ (2001) Oral topotecan as single-agent second-line chemotherapy in patients with advanced ovarian cancer. J Clin Oncol 19: $3967-3975$

Cortazar P, Johnson BE (1999) Review of the efficacy of individualized chemotherapy selected by in vitro drug sensitivity testing for patients with cancer. J Clin Oncol 17: 1625-1631

Crawford J, O’Rourke M, Schiller JH, Spiridonidis CH, Yanovich S, Ozer H, Langleben A, Hutchins L, Koletsky A, Clamon G, Burman S, White R, Hohneker J, Spiridonidis CH (1996) Randomized trial of vinorelbine compared with fluorouracil plus leucovorin in patients with stage IV non-small-cell lung cancer. J Clin Oncol 14: 2774-2784

Creemers GJ, Bolis G, Gore M, Scarfone G, Lacave AJ, Guastalla JP, Despax R, Favalli G, Kreinberg R, Van Belle S, Hudson I, Verweij J, ten Bokkel Huinink WW (1996) Topotecan, an active drug in the second-line treatment of epithelial ovarian cancer: results of a large European phase II study. J Clin Oncol 14: 3056-3061

Depierre A, von Pawel J, Hans K, Moro D, Clark P, Gatzemeier U, Paillot N, Scheithauer W, Carmichael J, Santoro A, Ross G, Marangolo M (1997) Evaluation of topotecan $\left(\right.$ Hycamtin $\left.^{\text {nit }}\right)$ in relapsed small cell lung cancer (SCLC). A multicentre phase II study (abstract). Lung Cancer 18(Suppl. 1): 35

Eckardt J, Gralla R, Palmer MC, Gandara D, Laplante J, Sandler A, Fields SZ, Fitts D, Broom C (1996) Topotecan (T) as second-line therapy in patients (Pts) with small cell lung cancer (SCLC): a phase II study (abstract). Ann Oncol 7(Suppl. 5): 107

Feinstein AR (1998) Clinical Epidemiology: The Architecture of Clinical Research. Philadelphia: W.B. Sanders

Fiorica J, Holloway R, Ndubisi B, Orr J, Grendys E, Boothby R, DeCesare S, LaPolla J, Hoffman M, Patel J (2002) Phase II trial of topotecan and cisplatin in persistent or recurrent squamous and nonsquamous carcinomas of the cervix. Gynecol Oncol 85: 89-94

Frasci G, Panza N, Comella P, Carteni G, Guida T, Nicolella GP, Natale M, Lombardi R, Apicella A, Pacilio C, Gravina A, Lapenta L, Comella G (1999) Cisplatin-topotecan-paclitaxel weekly administration with GCSF support for ovarian and small-cell lung cancer patients: a dosefinding study. Ann Oncol 10: 355-358

Guarino MJ, Schneider CJ, Grubbs SS, Biggs DD, Himelstein AL, Hogaboom K, Tilak S (2002) A dose-escalation study of weekly topotecan, cisplatin, and gemcitabine front-line therapy in patients with inoperable non-small cell lung cancer. Oncologist 7: 509-515

Hainsworth JD, Burris III HA, Morrissey LH, Greco FA (1999) Phase I trial of paclitaxel, carboplatin, and topotecan with or without filgrastim (granulocyte-colony stimulating factor) in the treatment of patients with advanced, refractory cancer. Cancer 85: $1179-1185$

Hays WL (1994) Statistics 5th edn. International Thomson Publishing.

Hochster H, Wadler S, Runowicz C, Liebes L, Cohen H, Wallach R, Sorich J, Taubes B, Speyer J (1999) Activity and pharmacodynamics of 21-day topotecan infusion in patients with ovarian cancer previously treated with platinum-based chemotherapy. J Clin Oncol 17: 2553-2561

Homesley HD, Hall DJ, Martin DA, Lewandowski GS, Vaccarello L, Nahhas WA, Suggs CL, Penley RG (2001) A dose-escalating study of weekly bolus topotecan in previously treated ovarian cancer patients. Gynecol Onco 83: $394-399$

Hoskins P, Eisenhauer E, Beare S, Roy M, Drouin P, Stuart G, Bryson P, Grimshaw R, Capstick V, Zee B (1998) Randomized phase II study of two schedules of topotecan in previously treated patients with ovarian cancer: a National Cancer Institute of Canada Clinical Trials Group study. J Clin Oncol 16: 2233-2237

Hudes GR, Kosierowski R, Greenberg R, Ramsey HE, Fox SC, Ozols RF, McAleer CA, Giantonio BJ (1995) Phase II study of topotecan in metastatic hormone-refractory prostate cancer. Invest New Drugs 13: $235-240$

Jacobs SA, Jett JR, Belani CP, Long GS, Day RD, Kim HD, Levitt ML, Woolley PV (1999) Topotecan and paclitaxel, an active couplet, in untreated extensive disease small cell lung cancer (abstract). Proc Am Soc Clin Oncol 18: 470a

Kingsbury WD, Boehm JC, Jakas DR, Holden KG, Hecht SM, Gallagher G, Caranfa MJ, McCabe FL, Faucette LF, Johnson RK, Hertzberg RP (1991) Synthesis of water-soluble (aminoalkyl) camptothecin analogues: inhibition of topoisomerase I and antitumor activity. J Med Chem 34: 98-107

Kirk RE (1982) Experimental Design: Procedure for The Behavorial Sciences. Pacific Grove, CA: Brooks/Cole Publishing Company

Kudelka AP, Tresukosol D, Edwards CL, Freedman RS, Levenback C, Chantarawiroj P, Gonzalez de Leon C, Kim EE, Madden T, Wallin B, Hord M, Verschraegen C, Raber M, Kavanagh JJ (1996) Phase II study of intravenous topotecan as a 5-day infusion for refractory epithelial ovarian carcinoma. J Clin Oncol 14: $1552-1557$

Lemkin PF, Thornwall CG, Walton KD, Hennighausen L. (2000) Themicroarray explorer to for data mining of cDNA microarrays: application for the mammary gland. Nucleic Acids Res 28: 4452-4459

Levine G (1991) A Guide to SPSS for Analysis of Variance. Hove: Lawrence Erlbaum Associates

Levine EG, Cirrincione CT, Szatrowski TP, Canellos G, Norton L, Henderson IC (1999) Phase II trial of topotecan in advanced breast cancer: a Cancer and Leukemia Group B study. Am J Clin Oncol 22: 218 222

Lynch Jr TJ, Kalish L, Strauss G, Elias A, Skarin A, Shulman LN, Posner M, Frei III E (1994) Phase II study of topotecan in metastatic non-small-cell lung cancer. J Clin Oncol 12: 347-352

McGuire WP, Blessing JA, Bookman MA, Lentz SS, Dunton CJ (2000) Topotecan has substantial antitumor activity as first-line salvage therapy in platinum-sensitive epithelial ovarian carcinoma: a Gynecologic Oncology Group Study. J Clin Oncol 18: $1062-1067$

Nagourney R, Brewer C, Radecki S, Kidder W, Sommers B, Evans S, Minor D, DiSaia PJ (2003) A phase II trial of gemcitabine plus cisplatin repeating doublet therapy in previously treated, relapsed ovarian cancer patients. Gynecol Oncol 88: 35-39

Nagourney RA, Link JS, Blitzer JB, Forsthoff C, Evans SS (2000) Gemcitabine plus cisplatin repeating doublet therapy in previously treated, relapsed breast cancer patients. J Clin Oncol 18: 2245-2249

O'Neill P, Clark PI, Smith D, Marshall E, Hannigan K, Ross G (2001) A phase I trial of a 5-day schedule of intravenous topotecan and etoposide in previously untreated patients with small-cell lung cancer. Oncology 61(Suppl. 1): 25-29

Perez-Soler R, Fossella FV, Glisson BS, Lee JS, Murphy WK, Shin DM, Kemp BL, Lee JJ, Kane J, Robinson RA, Lippman SM, Kurie JM, Huber MH, Raber MN, Hong WK (1996) Phase II study of topotecan in patients with advanced non-small-cell lung cancer previously untreated with chemotherapy. J Clin Oncol 14: 503-513

Pujol JL, von Pawel J, Tumolo S, Martoni A, Hearn S, Fields SZ, Ross G (2001) Preliminary results of combined therapy with topotecan and carboplatin in advanced non-small-cell lung cancer. Oncology 61(Suppl. 1): $47-54$

Raymond E, Burris HA, Rowinsky EK, Eckardt JR, Rodriguez G, Smith L, Weiss G, Von Hoff DD (1997) Phase I study of daily times five topotecan and single injection of cisplatin in patients with previously untreated non-small-cell lung carcinoma. Ann Oncol 8: 1003-1008 
Reed JC (1999) Dysregulation of apoptosis in cancer. J Clin Oncol 17: 2941 2953

Rothenberg ML (1997) Topoisomerase I inhibitors: review and update. Ann Oncol 8: 837-855

Sehouli J, Lichtenegger W, Hindenburg HJ, Klare P, Keil E, Heinrich G, Elling D, Hieronimus-Reichel A, Oskay G, Blohmer J, Camara O, Ledwon P, Stengel D (2001) A phase II study of topotecan plus gemcitabine in the treatment of patients with relapsed ovarian cancer after failure of firstline chemotherapy with platin and paclitaxel (abstract). Proc Am Soc Clin Oncol 20: 216a

Shi LM, Myers TG, Fan Y, O'Connor PM, Paull KD, Friend SH, Weinstein IN (1998) Mining the National Cancer Institute anticancer drug discovery database: cluster analysis of ellipticine analogs with p53invese and central nervous system-selective patterns of activity. Mol Pharmacol 53: $241-251$

Stupp R, Bodmer A, Duvoisin B, Bauer J, Perey L, Bakr M, Ketterer N, Leyvraz $S$ (2001) Is cisplatin required for the treatment of non-small-cell lung cancer. Experience and preliminary results of a phase I/II trial with topotecan and vinorelbine. Oncology 61(Suppl. 1): 35-41

Su Y-Z, Sommers B, Horlick D, Harris C, Evans S, Nagourney R (2001) Synergy between topotecan and other cytotoxic drugs in human tumors (abstract). Proc Am Assoc Cancer Res 42: 253-254

Taguchi T, Tominaga T, Ogawa M, Ishida T, Morimoto K, Ogawa N (1994) A late phase II study of CPT-11 (irinotecan) in advanced breast cancer. CPT-11 Study Group on Breast Cancer). Gan To Kagaku Ryoho 21: $1017-1024$

ten Bokkel Huinink W, Gore M, Carmichael J, Gordon A, Malfetano J, Hudson I, Broom C, Scarabelli C, Davidson N, Spanczynski M, Bolis G, Malmström H, Coleman R, Fields SC, Heron JF (1997) Topotecan versus paclitaxel for the treatment of recurrent epithelial ovarian cancer. J Clin Oncol 15: 2183-2193
The Elderly Lung Cancer Vinorelbine Italian Study Group (1999) Effects of vinorelbine on quality of life and survival of elderly patients with advanced non-small-cell lung cancer. J Natl Cancer Inst 91: 66-72

Verweij J, Lund B, Beijnen J, Planting A, de Boer-Dennert M, Koier I, Rosing H, Hansen H (1993) Phase I and pharmacokinetics study of topotecan, a new topoisomerase I inhibitor. Ann Oncol 4: 673-678

von Pawel J, Gatzemeier U, Pujol JL, Moreau L, Bildat S, Ranson M, Richardson G, Steppert C, Riviere A, Camlett I, Lane S, Ross G (2001) Phase II comparator study of oral versus intravenous topotecan in patients with chemosensitive small-cell lung cancer. J Clin Oncol 19: $1743-1749$

von Pawel J, Schiller JH, Shepherd FA, Fields SZ, Kleisbauer JP, Chrysson NG, Stewart DJ, Clark PI, Palmer MC, Depierre A, Carmichael J, Krebs JB, Ross G, Lane SR, Gralla R (1999) Topotecan versus cyclophosphamide, doxorubicin, and vincristine for the treatment of recurrent small-cell lung cancer. J Clin Oncol 17: 658-667

Wall JG, Burris III HA, Von Hoff DD, Rodriguez G, Kneuper-Hall R, Shaffer D, O’Rourke T, Brown T, Weiss G, Clark G, McVea S, Brown J, Johnson R, Friedman C, Smith B, Mann WS, Kuhn J (1992) A phase I clinical and pharmacokinetic study of the topoisomerase I inhibitor topotecan (SK\&F 104864) given as an intravenous bolus every 21 days. Anticancer Drugs 3: $337-345$

Weitz JJ, Marschke Jr RF, Sloan JA, Grill JP, Jett JR, Knost JA, Hatfield AK, Zenk DW, Bate WW, Schaefer PL (2000) A randomized phase II trial of two schedules of topotecan for the treatment of advanced stage nonsmall cell lung cancer. Lung Cancer 28: $157-162$

Wiesenfeld M, Marks R, Grill J, Sloan J, Tazelaar H, Carroll T, Kugler J, Krook J (1997) A randomized phase II study of topotecan (TOPA) and cisplatin (CDDP) with filgrastim (G-CSF) versus topotecan and paclitaxel $\left(\right.$ Taxol $\left.^{\mathbb{R}}\right)$ with filgrastim in patients with advanced non-small cell lung cancer (abstract). Proc Am Soc Clin Oncol 16: 488a 